\title{
Childhood Nasal Cavity Carcinoma
}

National Cancer Institute

\section{Source}

National Cancer Institute. Childhood Nasal Cavity Carcinoma. NCI Thesaurus. Code

C118817.

A rare carcinoma of the nasal cavity that occurs during childhood. 